\title{
Visceral adiposity index and prognosis among patients with ischemic heart failure
}

\author{
Índice de adiposidade visceral e prognóstico em pacientes com insuficiência \\ cardíaca isquêmica
}

\author{
Patrícia Vogel', Airton Stein", Aline Marcadenti"l' \\ Department of Cardiology, Hospital Nossa Senhora da Conceição, Porto Alegre, RS, Brazil
}

\begin{abstract}
'BSC. Specialist in Clinical Nutrition, Institute of Education and Research, Hospital Moinhos de Vento (IEP/HMV), Porto Alegre, RS, Brazil.

"PhD. Professor, Department of Public Health, Universidade Federal de Ciências da Saúde de Porto Alegre (UFCSPA), Porto Alegre, RS, Brazil, Professor, Institute of Health Technology Assessment, Hospital Nossa Senhora da Conceição, Porto Alegre, RS, Brazil. "'PhD. Professor, Postgraduate Cardiology Program, Institute of Cardiology, Fundação Universitária de Cardiologia (IC/FUC), Porto Alegre, RS, Brazil, Professor, Department of Nutrition, Universidade Federal de Ciências da Saúde de Porto Alegre (UFCSPA), Porto Alegre, RS, Brazil.
\end{abstract}

\section{KEY WORDS: \\ Anthropometry. \\ Body mass index. \\ Heart failure. \\ Mortality. \\ Obesity, abdominal.}

PALAVRAS-CHAVE:

Antropometria.

Indice de massa corporal.

Insuficiência cardíaca.

Mortalidade.

Obesidade abdominal.

\begin{abstract}
CONTEXT AND OBJECTIVES: The obesity paradox has already been established in relation to heart failure, but it is not known which obesity indicator best reflects this phenomenon. The aim of this study was to evaluate the association between obesity indexes and mortality among patients with heart failure.

DESIGN AND SETTING: Cohort study conducted in the Department of Cardiology of Hospital Nossa Senhora da Conceição (Brazil).

METHODS: Clinical, demographic, socioeconomic, biochemical and anthropometric data on 116 patients aged 30 to 85 years with a diagnosis of heart failure were evaluated. Arm fat area, body mass index, body surface area, body adiposity index, lipid accumulation product (LAP) and visceral adiposity index (VAI) were calculated. Cox regression was used to perform survival analyses.

RESULTS: At baseline, the individuals with ischemic heart failure who remained alive showed higher VAI $(3.60 \pm 3.71$ versus $1.48 \pm 1.58 ; \mathrm{P}=0.04)$ and a trend towards higher $L A P$, in comparison with the individuals who died. After an average follow-up of 14.3 months, ischemic heart failure patients who had VAI $>1.21$ showed $78 \%$ lower risk of death ( $\mathrm{HR} 0.12 ; 95 \% \mathrm{Cl}: 0.02-0.67 ; \mathrm{P}=0.02)$ and the Kaplan-Meier survival curves showed better prognosis for these individuals ( $P=0.005$; log-rank test).

CONCLUSION: Our results suggest that $\mathrm{VAl}$ is a good predictor of better prognosis among ischemic heart failure patients.
\end{abstract}

\section{RESUMO}

CONTEXTO E OBJETIVOS: O paradoxo da obesidade já está consolidado na insuficiência cardíaca, mas não se sabe qual indicador de obesidade melhor reflete esse fenômeno. Este estudo teve como objetivo avaliar a associação entre índices de obesidade e a mortalidade entre pacientes com insuficiência cardíaca. TIPO DE ESTUDO E LOCAL: Estudo de coorte realizado no Departamento de Cardiologia do Hospital Nossa Senhora da Conceição (Brasil).

MÉTODOS: Foram incluídos 116 pacientes com diagnóstico de insuficiência cardíaca de 30 a 85 anos. Dados clínicos, demográicos, socioeconômicos, bioquímicos e antropométricos foram avaliados. Área de gordura do braço, índice de massa corporal, área de superfície corporal, índice de adiposidade corporal, produto da acumulação lipídica e índice de adiposidade visceral foram calculados; regressão de Cox foi usada para realizar análises de sobrevida.

RESULTADOS: No início do estudo, indivíduos com insuficiência cardíaca isquêmica que se mantiveram vivos mostraram valores mais elevados de índice de adiposidade visceral (3,60 $\pm 3,71$ contra 1,48 $\pm 1,58$, $P=0,04)$ e uma tendência para produto da acumulação lipídica maior quando comparados com os indivíduos que morreram. Após acompanhamento médio de 14,3 meses, os pacientes com insuficiência cardíaca isquêmica que apresentaram índice de adiposidade visceral > 1,21 tiveram 78\% menor risco de morrer (HR 0,12; IC 95\% 0,02-0,67, P =0,02) e as curvas de Kaplan-Meier para sobrevida mostraram melhor prognóstico nesses indivíduos ( $P=0,005$, teste log-rank).

CONCLUSÃO: Nossos resultados sugerem que o índice de adiposidade visceral é um bom preditor de melhor prognóstico em pacientes com insuficiência cardíaca isquêmica. 


\section{INTRODUCTION}

Heart failure is a complex clinical conditional and it is considered to be an important public health problem. Despite significant therapeutic advances, heart failure is highly associated with morbidity and mortality in both developed and developing countries. ${ }^{1}$

Obesity is a well-known risk factor for cardiovascular diseases, including heart failure. ${ }^{2-4}$ However, studies conducted among ischemic and non-ischemic heart failure patients have suggested that high adiposity indexes may be associated with better prognosis and longer survival than among patients with normal and lower weight. ${ }^{5,6}$ This association is known as the "obesity paradox" or "reverse epidemiology"7,8

Most studies on the obesity paradox use body mass index to assess overweight and detect possible associations with the prognosis. ${ }^{9,10}$ Although body mass index is the most common and practical method for classifying obesity, there has been some discussion about whether it is indeed a good marker for patients with chronic diseases. ${ }^{11-13}$ Studies have been conducted with the aim of evaluating the prognostic value of other adiposity measurements such as waist circumference ${ }^{14}$ and body composition assessed through cutaneous skinfolds, ${ }^{15}$ dual-energy X-ray absorptiometry (DEXA) or bioelectrical impedance analysis ${ }^{16,17}$ among subjects with heart failure.

The lipid accumulation product index ${ }^{18}$ and the visceral adiposity index ${ }^{11}$ have been proposed as indirect measurements of visceral adipose tissue and have been correlated with cardiometabolic risk, cardiovascular disease and mortality in the general population. ${ }^{19,20}$ The body adiposity index is an alternative to the body mass index for determining the percentage of body fat, ${ }^{21}$ and neck circumference has been characterized as a pathogenic fat depot correlated with visceral adipose tissue and worse metabolic profile. ${ }^{22}$ However, none of these adiposity measurements has been tested among patients with ischemic or non-ischemic heart failure, within the context of the obesity paradox.

The purpose of this study was to evaluate associations shown by indexes of general and abdominal obesity in relation to mortality, among patients with ischemic and non-ischemic heart failure.

\section{OBJECTIVE}

To evaluate associations shown by indexes of general and abdominal obesity in relation to mortality, among patients with ischemic and non-ischemic heart failure.

\section{METHODS}

\section{Setting and study design}

A cohort study was conducted between July 2011 and January 2013 in the Department of Cardiology, Hospital Nossa Senhora da Conceição (Porto Alegre, Rio Grande do Sul, Brazil), which provides healthcare within the National Health System that is used mostly by patients belonging to lower social classes. The research protocol was approved by the Research Ethics Committee of the Conceição Hospital Group (CEP-GHC no. 10-118) and all the patients signed a consent statement in order to participate.

A sample of 116 patients aged 30 to 85 years who were admitted to the Cardiology Unit of Hospital Nossa Senhora da Conceição due to complications and symptoms relating to decompensated heart failure (for instance: dyspnea, fatigue or edema), of New York Heart Association classes I-IV, was consecutively selected. Patients with significant complications relating to heart failure (coronary artery disease, cerebrovascular disease or severe renal impairment) within the last 6 months, individuals with acute coronary syndrome within the last 90 days, patients with valvular heart disease, candidates for myocardial revascularization surgery, patients with a history of cancer over the last two years and patients who were not on a condition in which anthropometric data could be verified (those with amputation of lower limbs or sequelae of stroke) were excluded.

At baseline, demographic data (age, sex and self-reported skin color) and information regarding education (years at school) and lifestyle characteristics (smoking, abusive alcohol consumption [ $\geq 30 \mathrm{~g}$ for men and $\geq 15 \mathrm{~g}$ for women] and physical activity) were collected by trained personnel (physicians, medical students and nutritionists) using a standardized questionnaire. Clinical data were obtained directly from the medical records or after medical evaluation: angina (stable or unstable) was diagnosed by a trained cardiologist in accordance with current guidelines through reviewing the patient's electronic medical records; ${ }^{23}$ atrial fibrillation was also defined by a trained cardiologist in accordance with the guidelines and after cardiac auscultation; ${ }^{24}$ and blood pressure measurements were made using an aneroid sphygmomanometer with an adequately sized cuff around the arm circumference. Hypertension was defined as a diagnosis of systolic blood pressure $\geq 140$ and/or diastolic blood pressure $\geq 90 \mathrm{mmHg}$, from a previous medical diagnosis or through use of antihypertensive pressure-lowering agents. ${ }^{24}$ Fasting blood glucose $\geq 126 \mathrm{mg} / \mathrm{dl}$ or glycated hemoglobin $\geq 6.5 \%$ or a previous medical diagnosis were used to detect patients with type 2 diabetes mellitus. ${ }^{25}$ Ejection fraction values, in percentages, were obtained from color Doppler-derived measurements on tissues, by means of transthoracic echocardiography, performed using the GE Vivid 3 system (General Electric, Norway).

Complete blood count, serum creatinine, HDL-cholesterol, serum triglycerides, glycated hemoglobin and fasting blood glucose were obtained from $10 \mathrm{ml}$ venous blood samples from the patient, using standardized techniques at the hospital's certified laboratory. Hematological parameters were detected using a Sysmex XE-5000 analyzer (Sysmex, Kobe, Japan); serum creatinine values were obtained through the kinetic colorimetric Jaffé method; HDL-cholesterol and triglyceride levels were detected by means of the colorimetric enzymatic method; glycated 
hemoglobin levels were examined through electrochemiluminescence; and fasting blood glucose values were obtained using the modified hexokinase enzymatic method.

After hospital discharge, the patients were contacted every six months by telephone to collect information about their vital status. All patients were contacted at least three times during the follow-up. In cases of death, this was confirmed from the medical records and/or the death certificate, which was brought to the researchers by a member of the family.

\section{Anthropometric parameters}

Weight, height, arm circumference, neck circumference, waist circumference, hip circumference and triceps skinfold thickness measurements were obtained. Weight $(\mathrm{kg})$ was measured with the patients wearing light clothes and barefoot, standing on weighing scales with scale divisions of $100 \mathrm{~g}$ (Filizola model 31, São Paulo, Brazil), and height was obtained using a stadiometer with scale divisions of $0.1 \mathrm{~cm}$ (Tonelli model E120 A; IN Tonelli SA, Santa Catarina, Brazil). Circumferences were measured with a nonelastic measuring tape. Arm circumference was obtained at the midpoint between the acromion and the olecranon, with the arm extended down the side of the body and the palm of the hand facing the thigh. Waist circumference was measured at the largest part between the waist and the thigh, while the subjects were wearing thin clothes. the narrowest part between the hips and the ribs. The triceps skinfold thickness was measured using a plicometer at the midpoint between the acromion and the olecranon with the arm extended down the side of the body and the palm of the hand facing the thigh. ${ }^{26}$ Neck circumference was obtained from the midpoint of the neck. ${ }^{27}$

Adiposity measurements were calculated as follows:

- Arm fat area $\left(\mathrm{cm}^{2}\right)=\left(\right.$ arm circumference $(\mathrm{cm})^{*}[$ triceps skinfold thickness $(\mathrm{mm}) / 10] / 2)-\left(3.14^{\star}\right.$ [triceps skinfold thickness $\left.(\mathrm{mm}) / 10]^{2} / 4\right)$. The $90^{\text {th }}$ percentile was taken to be the cutoff point for obesity. ${ }^{28}$

- Body mass index $\left(\mathrm{kg} / \mathrm{m}^{2}\right)=$ weight $(\mathrm{kg}) /$ height $^{2}(\mathrm{~m})$. The cutoff point for obesity was taken to be $\geq 30 \mathrm{~kg} / \mathrm{m}^{2}{ }^{29}$

- Body surface area $\left(\mathrm{m}^{2}\right)=\left(0.007184^{\star}(\text { height }(\mathrm{cm}))^{0.725}\right)^{\star}($ weight $\left.(\mathrm{kg})^{0.425}\right) \cdot{ }^{30}$

- Body adiposity index $(\%)=$ (hip circumference $(\mathrm{cm}) /$ (height $\left.)^{1.5}\right)-18 .^{21}$

- $\quad$ Lipid accumulation product index $(\mathrm{cm} . \mathrm{mmol} . \mathrm{l})=$ (waist circumference $(\mathrm{cm})-65)^{\star}$ triglycerides $(\mathrm{mmol} / \mathrm{l})$ for males; and lipid accumulation product index $=$ (waist circumference $(\mathrm{cm})-58)^{*}$ triglycerides $(\mathrm{mmol} / \mathrm{l})$ for females. ${ }^{18}$

- Visceral adiposity index $=$ (waist circumference $(\mathrm{cm}) /$ $\left(39.68+\left(1.88^{\star} \text { body mass index }\right)\right)^{\star}(\text { triglycerides } / 1.03)^{\star}(1.31 /$ $\mathrm{HDL}$ ) for males; and visceral adiposity index $=$ (waist circumference $(\mathrm{cm}) /\left(36.58+\left(1.89^{*} \text { body mass index }\right)\right)^{*}($ triglycerides $/ 0.81)^{\star}(1.52 / \mathrm{HDL})$ for females. ${ }^{11}$

\section{Statistical analysis}

Analyses were performed in accordance with the etiology of heart failure (ischemic or non-ischemic), in order to explore the possible role of the etiology in relation to anthropometric indexes and mortality. Data were expressed as mean \pm standard deviation or as frequencies (\%). Student's t test (parametric variables), Wilcoxon and Mann-Whitney tests (nonparametric variables) and Fisher's exact test (categorical variables) were used for comparisons. We used the log-rank test, KaplanMeier curves and Cox regression model for survival analyses. All anthropometric data were categorized as percentiles, and the reference category was defined as $\geq 25^{\text {th }}$ percentile. The lipid accumulation product index, visceral adiposity index and body adiposity index do not have specific cut-off points, but all the adiposity indexes were standardized at the $25^{\text {th }}$ percentile in order to maintain comparability.

Analyses were performed using the Statistical Package for the Social Sciences (SPSS) software, version 17.0 (SPSS, IL, USA). For each analysis, $\boldsymbol{\alpha}$-level $=0.05$ was considered significant, and 95\% confidence intervals were shown.

\section{RESULTS}

During the follow-up period (mean duration of $14.3 \pm 10.2$ months), the general mortality rate was $20.6 \%$. It was $30 \%$ (six deaths) among the patients with ischemic heart failure and $18.8 \%$ (18 deaths) among those with non-ischemic heart failure. No statistically significant correlation was identified between the heart failure etiology and mortality rate $(\mathrm{P}=0.3)$.

The patients' mean age was $61.8 \pm 12.3$ years; $62.1 \%$ were males; $71.6 \%$ were whites; the mean number of years of school attendance was $5.0 \pm 3.4 ; 12.1 \%$ were current smokers; and $8.6 \%$ presented abusive consumption of alcohol. According to the body mass index, 41 (35.4\%), 36 (31\%) and 39 (33.6\%) presented, respectively, normal weight, overweight and obesity. Regarding the New York Heart Association functional class, 88 (75.9\%) were in classes III-IV. The mean ejection fraction was $40.6 \pm$ $14.8 \%$. The prevalences of hypertension and type 2 diabetes mellitus were $77.6 \%$ and $32.8 \%$ respectively.

Table 1 shows the patients' demographic and clinical characteristics, stratified according to heart failure etiology and survival. Among the patients with ischemic heart failure, there were no differences regarding age, ethnicity, New York Heart Association classification, ejection fraction, systolic and diastolic blood pressure, hemoglobin levels, diagnoses of hypertension, angina, atrial fibrillation or type 2 diabetes mellitus, or the number of drugs in use according to survival status (dead or alive). However, there was a trend for serum creatinine levels $(\mathrm{P}=0.07)$. Among the individuals with non-ischemic heart failure, only hemoglobin levels were significantly lower in the group of patients who died $(\mathrm{P}=0.01)$. 
Regarding the main drugs used within the hospital setting, 101 patients $(87.1 \%)$ were being treated with loop diuretics, 93 $(80.2 \%)$ with beta blockers, $71(61.2 \%)$ with platelet anticoagulant, 68 (58.6\%) with angiotensin-converting-enzyme inhibitors, 55 (47.4\%) with statins, 49 (42.2\%) with potassium-sparing diuretics, 46 (39.7\%) with digitalis, 39 (33.6\%) with oral anticoagulants, 18 (15.5\%) with angiotensin receptor blockers and 13 (11.2\%) with calcium channel blockers.

The adiposity indexes according to heart failure etiology and survival status are described in Table 2. There were no significant differences in most of the anthropometric parameters, except for the visceral adiposity index and a trend for lipid accumulation product index values among individuals with ischemic heart failure, which were both higher among survivors than among patients who died $(3.60 \pm 3.71$ versus $1.48 \pm 1.58$; $\mathrm{P}=0.04$ for visceral adiposity index; and $70.49 \pm 50.73$ versus $35.49 \pm 32.62$; $\mathrm{P}=0.08$ for lipid accumulation product index).

Survival analyses performed using the Cox regression model showed that higher values for the visceral adiposity index $(>1.21)$ were related to better prognosis (HR 0.12; 95\% CI: 0.02-0.67;

Table 1. Demographic and clinical characteristics of the sample [mean \pm SD or $n(\%)$ ]

\begin{tabular}{|c|c|c|c|c|c|c|}
\hline & \multicolumn{3}{|c|}{ Ischemic $(n=20)$} & \multicolumn{3}{|c|}{ Non-ischemic $(n=96)$} \\
\hline & $\operatorname{Died}(n=6)$ & Survived $(n=14)$ & $\mathbf{P}$ & Died $(n=18)$ & Survived $(n=78)$ & $\mathbf{P}$ \\
\hline Age (years) & $71.7 \pm 13.2$ & $67.1 \pm 10.9$ & 0.43 & $57.2 \pm 11.5$ & $61.2 \pm 12.1$ & 0.20 \\
\hline \multicolumn{7}{|l|}{ Ethnicity } \\
\hline White & $5(33.3)$ & $10(66.7)$ & 0.57 & $14(20.6)$ & $54(79.4)$ & 0.47 \\
\hline Nonwhite & $1(20.0)$ & $4(80.0)$ & & $4(14.3)$ & $24(85.7)$ & \\
\hline \multicolumn{7}{|c|}{ New York Heart Association Functional Class } \\
\hline Ejection fraction (\%) & $46.0 \pm 15.3$ & $40.8 \pm 12.9$ & 0.44 & $34.9 \pm 13.9$ & $41.7 \pm 15.3$ & 0.10 \\
\hline Systolic blood pressure (mmHg) & $137.8 \pm 23.4$ & $123.3 \pm 13.7$ & 0.13 & $120.0 \pm 19.0$ & $120.5 \pm 17.8$ & 0.91 \\
\hline Diastolic blood pressure (mmHg) & $85.0 \pm 18.7$ & $74.7 \pm 11.1$ & 0.17 & $74.1 \pm 12.8$ & $73.9 \pm 10.3$ & 0.94 \\
\hline Hemoglobin (mg/dl) & $12.5 \pm 1.5$ & $12.6 \pm 2.5$ & 0.92 & $11.9 \pm 2.3$ & $13.3 \pm 1.9$ & 0.01 \\
\hline Creatinine (mg/dl) & $1.15 \pm 0.46$ & $1.70 \pm 0.62$ & 0.07 & $1.41 \pm 0.94$ & $1.25 \pm 0.43$ & 0.28 \\
\hline \multicolumn{7}{|l|}{ Type 2 diabetes mellitus } \\
\hline \multicolumn{7}{|l|}{ Hypertension } \\
\hline Yes & $5(27.8)$ & $13(72.2)$ & 0.52 & $13(18.1)$ & $59(81.9)$ & 0.76 \\
\hline No & $1(50.0)$ & $1(50.0)$ & & $5(21.7)$ & $18(78.3)$ & \\
\hline \multicolumn{7}{|l|}{ Angina } \\
\hline Yes & $1(33.3)$ & $2(66.7)$ & 0.89 & $6(20.0)$ & $24(80.0)$ & 0.83 \\
\hline No & $5(29.4)$ & $12(70.6)$ & & $12(18.2)$ & $54(81.8)$ & \\
\hline \multicolumn{7}{|l|}{ Atrial fibrillation } \\
\hline Yes & $2(66.7)$ & $1(33.3)$ & 0.28 & $1(6.2)$ & $15(93.8)$ & 0.36 \\
\hline No & $4(23.5)$ & $13(76.5)$ & & $5(83.3)$ & $1(16.7)$ & \\
\hline Number of drugs in use & $6.7 \pm 1.9$ & $6.3 \pm 1.3$ & 0.59 & $5.6 \pm 1.9$ & $5.6 \pm 1.4$ & 0.97 \\
\hline
\end{tabular}

SD $=$ standard deviation

Table 2. Anthropometric characteristics of the sample (mean \pm SD)

\begin{tabular}{|c|c|c|c|c|c|c|}
\hline & \multicolumn{3}{|c|}{ Ischemic $(n=20)$} & \multicolumn{3}{|c|}{ Non-ischemic $(n=96)$} \\
\hline & Died $(n=6)$ & Survived $(n=14)$ & $\mathbf{P}$ & Died $(n=18)$ & Survived ( $n=78$ ) & $\mathbf{P}$ \\
\hline Arm fat area $\left(\mathrm{cm}^{2}\right)$ & $29.5 \pm 14.7$ & $29.1 \pm 14.2$ & $0.95^{*}$ & $28.6 \pm 14.7$ & $34.4 \pm 25.4$ & $0.74^{+}$ \\
\hline Neck circumference $(\mathrm{cm})$ & $36.7 \pm 6.8$ & $38.6 \pm 2.2$ & $0.34^{*}$ & $37.4 \pm 3.7$ & $38.1 \pm 4.4$ & $0.56^{*}$ \\
\hline Waist circumference (cm) & $96.3 \pm 13.2$ & $97.1 \pm 5.6$ & $0.87^{*}$ & $98.8 \pm 11.7$ & $99.7 \pm 17.3$ & $0.83^{*}$ \\
\hline Body mass index $\left(\mathrm{kg} / \mathrm{m}^{2}\right)$ & $27.4 \pm 4.9$ & $26.8 \pm 2.6$ & $0.78^{*}$ & $27.9 \pm 5.3$ & $29.1 \pm 7.4$ & $0.50^{*}$ \\
\hline Body surface area $\left(\mathrm{m}^{2}\right)$ & $1.79 \pm 0.16$ & $1.80 \pm 0.14$ & $0.96^{*}$ & $1.87 \pm 0.21$ & $1.89 \pm 0.28$ & $0.76^{*}$ \\
\hline Body adiposity index (\%) & $30.5 \pm 8.5$ & $29.1 \pm 4.9$ & $0.66^{*}$ & $30.4 \pm 7.5$ & $31.9 \pm 7.9$ & $0.46^{*}$ \\
\hline Lipid accumulation product index (LAP, cm.mmol.I) & $35.49 \pm 32.62$ & $70.49 \pm 50.73$ & $0.08^{\dagger}$ & $57.66 \pm 71.64$ & $58.22 \pm 53.42$ & $0.72^{+}$ \\
\hline Visceral adiposity index & $1.48 \pm 1.58$ & $3.60 \pm 3.71$ & $0.04^{+}$ & $2.77 \pm 2.63$ & $2.69 \pm 2.43$ & $0.71^{\dagger}$ \\
\hline
\end{tabular}

SD = standard deviation. *Student's t test (parametric variables), taking P < 0.05 (5\%) to be significant; 'Wilcoxon and Mann-Whitney tests (nonparametric variables) for comparison, taking $\mathrm{P}<0.05$ (5\%) to be significant. 
$\mathrm{P}=0.02$ ) among patients with ischemic heart failure etiology. Kaplan-Meier survival curves plotted for patients with ischemic heart failure etiology showed that survival prognosis improved with visceral adiposity index values $>1.21(\mathrm{P}=0.005$ detected by means of the log-rank test) (Figure 1). Other anthropometric data did not show any relationship with prognosis in survival analyses.

\section{DISCUSSION}

To our knowledge, this is the first study on patients with heart failure to have evaluated non-traditional adiposity indexes as prognostic markers. Moreover, our study showed an inverse relationship between the visceral adiposity index as an abdominal obesity index and mortality, among patients with ischemic heart failure, and we were unable to find associations between general adiposity indexes (body adiposity index and body mass index) and survival in our population.

The obesity paradox has been widely studied, but controversy remains with regard to the best adiposity index for making the prognosis among individuals with ischemic and non-ischemic heart failure. A meta-analysis that evaluated nine studies and included 28,209 individuals with heart failure showed that overweight (body mass index $25-29.9 \mathrm{~kg} / \mathrm{m}^{2}$ ) and obesity (body mass index $\geq 30 \mathrm{~kg} / \mathrm{m}^{2}$ ) detected by means of body mass index cutoff points were associated with lower cardiovascular and all-causes mortality. ${ }^{8}$ Among individuals with heart failure and type 2 diabetes mellitus, body mass index $25-30 \mathrm{~kg} / \mathrm{m}^{2}$ was also correlated with lower mortality. ${ }^{31}$ On the other hand, obesity class III (body mass index $\geq 40 \mathrm{~kg} / \mathrm{m}^{2}$ ) was correlated with higher mortality rates. ${ }^{32,33}$

Although higher body mass index $\left(\geq 25 \mathrm{~kg} / \mathrm{m}^{2}\right)$ has been commonly correlated with a favorable prognosis, a meta-analysis including 12 studies and 6,142 individuals with acute

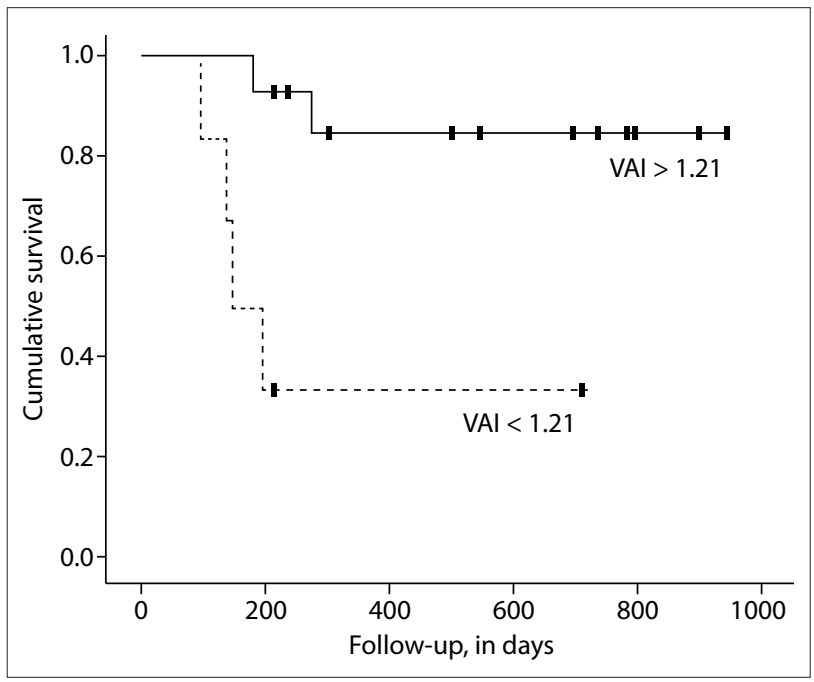

Figure 1. Kaplan-Meier survival curves plotted for patients with ischemic heart failure etiology (VAl: visceral adiposity index). decompensated heart failure showed that higher body mass index was associated with lower mortality, particularly among very elderly people (age $>75$ years), individuals with reduced ejection fraction (<50\%), people without type 2 diabetes mellitus and cases of newly diagnosed heart failure. This suggested that aging, heart failure severity/chronicity and metabolism might explain the obesity paradox regarding use of the body mass index as an adiposity measure. ${ }^{34}$ Moreover, among obese individuals with heart failure, symptoms may appear earlier, and therefore the diagnosis and treatment can take place at earlier stages of heart failure.

We were unable to find any association with body mass index and mortality according to heart failure etiology, and other authors have shown conflicting results. Among chronic heart failure patients, after a mean follow up of 30.7 months (annual event rate $6.0 \%$ ), the ischemic heart failure overweight subgroup had a lower survival rate than the non-ischemic heart failure overweight subgroup; however, normal weight and obese individuals showed no difference regarding mortality and heart failure etiology. ${ }^{5}$ Among individuals with chronic heart failure classes II and III, the obesity paradox was only observed in patients with nonischemic heart failure after adjustment for age, sex, New York Heart Association functional class, ejection fraction, comorbidities and treatment. ${ }^{6}$ These studies were conducted among individuals who were in a stable condition and receiving outpatient treatment, whereas our patients were evaluated in a hospital setting and had higher prevalence of New York Heart Association functional classes III and IV. Thus, it can be suggested that heart failure severity strongly contributes towards mortality independently of heart failure etiology and body mass index values.

Using body mass index as a body fat measurement may lead to misclassification of around $40 \%$ of patients with heart failure ${ }^{35}$ and the usefulness of body mass index for evaluating body composition in these subjects has been questioned. ${ }^{10,12}$ Body mass index does not detect the total amount of body fat ${ }^{12,35,36}$ and its classification does not vary according to sex, age or ethnicity. ${ }^{36}$ As well as in cases of heart failure, the obesity paradox has been shown in other cardiovascular disorders such as coronary artery disease. ${ }^{37}$ Grade I obesity has not been associated with mortality among the general population. ${ }^{38}$ However, body mass index has a good correlation with lean mass among individuals with coronary artery disease ${ }^{13}$ and also in the general population. ${ }^{12}$ Thus, the poor diagnostic performance of body mass index in discriminating fat and lean mass and also in assessing body fat content could explain the obesity paradox. Furthermore, the prognostic value of the body mass index in specific situations, such as athletes and patients with fluid accumulation, is also limited. ${ }^{12}$

The effects of body fat detected through other assessment measurements such as cutaneous skinfolds, bioelectrical impedance analysis and DEXA on the obesity paradox have also being 
studied, given the limitations of the body mass index. Increased body fat detected through DEXA has been correlated with lower mortality among cases of heart failure. ${ }^{35}$ However, these techniques are not always available and may be expensive, thus restricting their use in clinical practice. The body adiposity index is a simple alternative to the body mass index for detecting percentage body fat; however, we were unable to detect any association between higher body adiposity index and survival among cases of heart failure. It has been suggested that using the body adiposity index as an indicator of overall adiposity is likely to produce biased estimates of percentage body fat, in which the errors may vary according to sex and level of body fatness. Thus, estimates based on the body adiposity index may not be more accurate than those based on the body mass index. ${ }^{39}$

The prognostic value of waist circumference as an abdominal obesity index has also been studied among patients with heart failure. Interestingly, higher waist circumference values have been shown to have a protective role regarding mortality rates among patients with heart failure. ${ }^{7,14}$ Increased waist circumference and normal body mass index may reflect lower levels of physical activity among healthy individuals, with consequently higher levels of fat mass and lower lean mass. ${ }^{40}$ However, waist circumference has been correlated with both lean and fat mass detected by means of bioelectrical impedance analysis among individuals with heart failure, thus suggesting that both compartments are associated with a better prognosis among these patients. ${ }^{17}$

Waist circumference cannot distinguish subcutaneous adipose tissue from visceral adipose tissue, but it seems to be more strongly associated with subcutaneous fat, especially among overweight individuals. ${ }^{41}$ Higher levels of visceral fat have been correlated with higher levels of inflammatory cytokines such as tumor necrosis factor- $\alpha$, which have catabolic effects on lean mass and may contribute towards cardiac cachexia. ${ }^{42,43}$ However, tumor necrosis factor- $\alpha$ receptors are highly expressed in subcutaneous adipose tissue, ${ }^{44}$ and heart failure patients with an enlarged waist may be protected from the negative impact of increased levels of tumor necrosis factor- $\alpha$ through production of higher levels of these receptors, compared with patients with normal weight or who are underweight. ${ }^{7}$ Since weight lost is associated with lower survival in situations of heart failure, ${ }^{45}$ patients with greater severity of heart failure who also have excess body fat (including both the subcutaneous and the visceral compartment) may have greater metabolic reserves and be more resistant to the increased catabolic burden. ${ }^{46}$

Obese individuals and patients with ischemic heart disease have higher levels of lipoproteins such as cholesterol and chylomicron, and this contributes towards higher bacterial lipopolysaccharide levels, thereby stimulating release of proinflammatory cytokines. ${ }^{47,48}$ Anthropometric and serum lipid values are needed in order to calculate both the lipid accumulation product index and visceral adiposity index. However, the formula for the visceral adiposity index includes two biomarkers that relate to lipoproteins (HDL-cholesterol and triglycerides) and two obesity indexes that are associated with lean mass and subcutaneous fat (waist circumference and body mass index), thus suggesting that instead of being a "visceral adipose function" as proposed originally, ${ }^{11}$ the visceral adiposity index might reflect an "excess of weight function" among patients with heart failure.

This exploratory study may have been influenced by the small sample size, which will have conferred higher variability, and it may have lacked power to detect some associations, such as the lipid accumulation product index and death. Thus, some of our results may have been due to chance. Furthermore, we did not construct an adjusted multivariable model to detect independent associations between anthropometric indexes (especially the visceral adiposity index) and mortality. Our patients were relatively young and were predominantly in New York Heart Association classes III-IV, without a preserved ejection fraction, which may have limited the extrapolation of our results. On the other hand, the data collection was prospective, which considerably improves data quality. In addition, important prognostic factors were considered in our analysis.

\section{CONCLUSION}

We suggest that the visceral adiposity index may be a good predictor of mortality among patients with ischemic heart failure. However, further studies are needed in order to confirm these results.

\section{REFERENCES}

1. Mosterd A, Hoes AW. Clinical epidemiology of heart failure. Heart. 2007;93(9):1137-46.

2. Kenchaiah S, Sesso HD, Gaziano JM. Body mass index and vigorous physical activity and the risk of heart failure among men. Circulation. 2009;119(1):44-52.

3. Kenchaiah S, Evans JC, Levy D, et al. Obesity and the risk of heart failure. N Engl J Med. 2002;347(5):305-13

4. Curtis JP, Selter JG, Wang Y, et al. The obesity paradox: body mass index and outcomes in patients with heart failure. Arch Intern Med. 2005;165(1):55-61.

5. Arena R, Myers J, Abella J, et al. Influence of etiology of heart failure on the obesity paradox. Am J Cardiol. 2009;104(8):1116-21.

6. Zamora E, Lupón J, de Antonio M, et al. The obesity paradox in heart failure: is etiology a key factor? Int J Cardiol. 2013;166(3):601-5.

7. Clark AL, Fonarow GC, Horwich TB. Waist circumference, body mass index, and survival in systolic heart failure: the obesity paradox revisited. J Card Fail. 2011;17(5):374-80.

8. Oreopoulos A, Padwal R, Kalantar-Zadeh K, et al. Body mass index and mortality in heart failure: a meta-analysis. Am Heart J. 2008;156(1):13-22. 
9. Shirley S, Davis LL, Carlson BW. The relationship between body mass index/body composition and survival in patients with heart failure. J Am Acad Nurse Pract. 2008;20(6):326-32.

10. Lavie CJ, Milani RV, Ventura HO, Romero-Corral A. Body composition and heart failure prevalence and prognosis: getting to the fat of the matter in the "obesity paradox". Mayo Clin Proc. 2010;85(7):605-8.

11. Amato MC, Giordano C, Galia M, et al.Visceral Adiposity Index: a reliable indicator of visceral fat function associated with cardiometabolic risk. Diabetes Care. 2010;33(4):920-2.

12. Romero-Corral A, Somers VK, Sierra-Johnson J, et al. Accuracy of body mass index in diagnosing obesity in the adult general population. Int J Obes (Lond.). 2008;32(6):959-66.

13. Romero-Corral A, Somers VK, Sierra-Johnson J, et al. Diagnostic performance of body mass index to detect obesity in patients with coronary artery disease. Eur Heart J. 2007;28(17):2087-93.

14. Clark AL, Chyu J, Horwich TB. The obesity paradox in men versus women with systolic heart failure. Am J Cardiol. 2012;110(1):77-82.

15. Lavie CJ, Osman AF, Milani RV, Mehra MR. Body composition and prognosis in chronic systolic heart failure: the obesity paradox. Am J Cardiol. 2003;91(7):891-4.

16. Colín-Ramírez E, Castillo-Martínez L, Orea-Tejeda A, et al. Bioelectrical impedance phase angle as a prognostic marker in chronic heart failure. Nutrition. 2012;28(9):901-5.

17. Thomas E, Clark AL, Fonarow GC, Horwich TB. Use of bioelectrical impedance analysis to assess body composition in heart failure patients. Journal of Cardiac Failure. 2012;18(8):S86. Available from: http://www.onlinejcf.com/article/S1071-9164\%2812\%2900715-4/ pdf. Accessed in 2015 (Dec 28).

18. Kahn HS. The "lipid accumulation product" performs better than the body mass index for recognizing cardiovascular risk: a populationbased comparison. BMC Cardiovasc Disord. 2005;5:26.

19. Mohammadreza B, Farzad H, Davoud K, Fereidoun Prof AF. Prognostic significance of the complex "Visceral Adiposity Index" vs. simple anthropometric measures: Tehran lipid and glucose study. Cardiovasc Diabetol. 2012;11:20

20. Bozorgmanesh M, Hadaegh F, Azizi F. Predictive performances of lipid accumulation product vs. adiposity measures for cardiovascular diseases and all-cause mortality, 8.6-year follow-up: Tehran lipid and glucose study. Lipids Health Dis. 2010;9:100.

21. Bergman RN, Stefanovski D, Buchanan TA, et al. A better index of body adiposity. Obesity (Silver Spring). 2011;19(5):1083-9.

22. Preis SR, Massaro JM, Hoffmann U, et al. Neck circumference as a novel measure of cardiometabolic risk: the Framingham Heart study. J Clin Endocrinol Metab. 2010;95(8):3701-10.

23. 2012 Writing Committee Members, Jneid H, Anderson JL, et al. 2012 ACCF/AHA focused update of the guideline for the management of patients with unstable angina/Non-ST-elevation myocardial infarction (updating the 2007 guideline and replacing the 2011 focused update): a report of the American College of Cardiology
Foundation/American Heart Association Task Force on practice guidelines. Circulation. 2012;126(7):875-910

24. January CT, Wann LS, Alpert JS, et al. 2014 AHA/ACC/HRS guideline for the management of patients with atrial fibrillation: a report of the American College of Cardiology/American Heart Association Task Force on practice guidelines and the Heart Rhythm Society. Circulation. 2014;130(23):e199-267.

25. Chobanian AV, Bakris GL, Black HR, et al. The Seventh Report of the Joint National Committee on Prevention, Detection, Evaluation, and Treatment of High Blood Pressure: the JNC 7 report. JAMA. 2003;289(19):2560-72.

26. Lohmann TG, Roche AF, Martorell R. Anthropometric standardization reference manual. Champaign: Human Kinetics Books; 1988.

27. Ben-Noun L, Sohar E, Laor A. Neck circumference as a simple screening measure for identifying overweight and obese patients. Obes Res. 2001;9(8):470-7.

28. Frisancho AR. Anthropometric standards for the assessment of growth and nutritional status. Michigan: The University of Michigan Press; 1990.

29. World Health Organization. BMI classification. Available from: http:// www.who.int/bmi/index.jsp?introPage=intro_3.html. Accessed in 2015 (Dec 28).

30. Du Bois D, Du Bois EF. A formula to estimate the approximate surface area if height and weight be known. Arch Int Med. 1916;17:863-71.

31. Costanzo P, Pellicori P, Cleland J, et al. 116 The obesity paradox in type II diabetes mellitus. Impact of body mass index on prognosis. Heart. 2014;100:A66. Available from: http://heart.bmj.com/content/100/ Suppl_3/A66.1. Accessed in 2015 (Dec 28).

32. Waring ME, Saczynski JS, McManus $D$, et al. Weight and mortality following heart failure hospitalization among diabetic patients. Am J Med. 2011;124(9):834-40.

33. Kapoor JR, Heidenreich PA. Obesity and survival in patients with heart failure and preserved systolic function: a U-shaped relationship. Am Heart J. 2010;159(1):75-80.

34. Shah R, Gayat E, Januzzi JL Jr, et al. Body mass index and mortality in acutely decompensated heart failure across the world: a global obesity paradox. J Am Coll Cardiol. 2014;63(8):778-85.

35. Oreopoulos A, Ezekowitz JA, McAlister FA, et al. Association between direct measures of body composition and prognostic factors in chronic heart failure. Mayo Clin Proc. 2010;85(7):609-17.

36. Lavie CJ, Milani RV, Ventura HO. Obesity and cardiovascular disease: risk factor, paradox, and impact of weight loss. J Am Coll Cardiol. 2009;53(21):1925-32.

37. Romero-Corral A, Montori VM, Somers VK, et al. Association of bodyweight with total mortality and with cardiovascular events in coronary artery disease: a systematic review of cohort studies. Lancet. 2006;368(9536):666-78.

38. Flegal KM, Kit BK, Orpana H, Graubard BI. Association of all-cause mortality with overweight and obesity using standard body mass index categories: a systematic review and meta-analysis. JAMA. 2013;309(1):71-82 
39. Freedman DS, Thornton JC, Pi-Sunyer FX, et al. The body adiposity index (hip circumference $\div$ height(1.5)) is not a more accurate measure of adiposity than is BMI, waist circumference, or hip circumference. Obesity (Silver Spring). 2012;20(12):2438-44.

40. Ross R, Katzmarzyk PT. Cardiorespiratory fitness is associated with diminished total and abdominal obesity independent of body mass index. Int J Obes Relat Metab Disord. 2003;27(2):204-10.

41. Bosy-Westphal A, Booke CA, Blöcker T, et al. Measurement site for waist circumference affects its accuracy as an index of visceral and abdominal subcutaneous fat in a Caucasian population. J Nutr. 2010;140(5):954-61.

42. Deswal A, Petersen NJ, Feldman AM, et al. Cytokines and cytokine receptors in advanced heartfailure: an analysis of the cytokines database from the Vesnarinone trial (VEST). Circulation. 2001;103(16):2055-9.

43. Kalantar-Zadeh K, Horwich TB, Oreopoulos A, et al. Risk factor paradox in wasting diseases. Curr Opin Clin Nutr Metab Care. 2007;10(4):433-42.

44. Mohamed-Ali V, Goodrick S, Bulmer K, et al. Production of soluble tumor necrosis factor receptors by human subcutaneous adipose tissue in vivo. Am J Physiol. 1999;277(6 Pt 1):E971-5.

45. Anker SD, Negassa A, Coats AJ, et al. Prognostic importance of weight loss in chronic heart failure and the effect of treatment with angiotensin-converting-enzyme inhibitors: an observational study. Lancet. 2003;361(9363):1077-83.

46. Arena R, Lavie CJ. The obesity paradox and outcome in heart failure: is excess bodyweight truly protective? Future Cardiol. 2010;6(1):1-6.

47. Sharma $R$, Bolger $A P$, Rauchhaus $M$, et al. Cellular endotoxin desensitization in patients with severe chronic heart failure. Eur J Heart Fail. 2005;7(5):865-8.

48. Kalantar-Zadeh K, Block G, Horwich T, Fonarow GC. Reverse epidemiology of conventional cardiovascular risk factors in patients with chronic heart failure. J Am Coll Cardiol. 2004;43(8):1439-44.

\section{Sources of funding: None}

Conflict of interests: None

Date of first submission: July 20, 2015

Last received: November 4, 2015

Accepted: November 21, 2015

\section{Address for correspondence:}

Aline Marcadenti

Department of Nutrition

Universidade Federal de Ciências da Saúde de Porto Alegre (UFCSPA)

Rua Sarmento Leite, 245

Porto Alegre (RS) - Brasil

CEP 90050-170

Tel. (+55 51) 3303-8830

Fax. (+55 51) 3303-8810

E-mail: marcadenti@yahoo.com.br 